\title{
Miguel Castanho
}

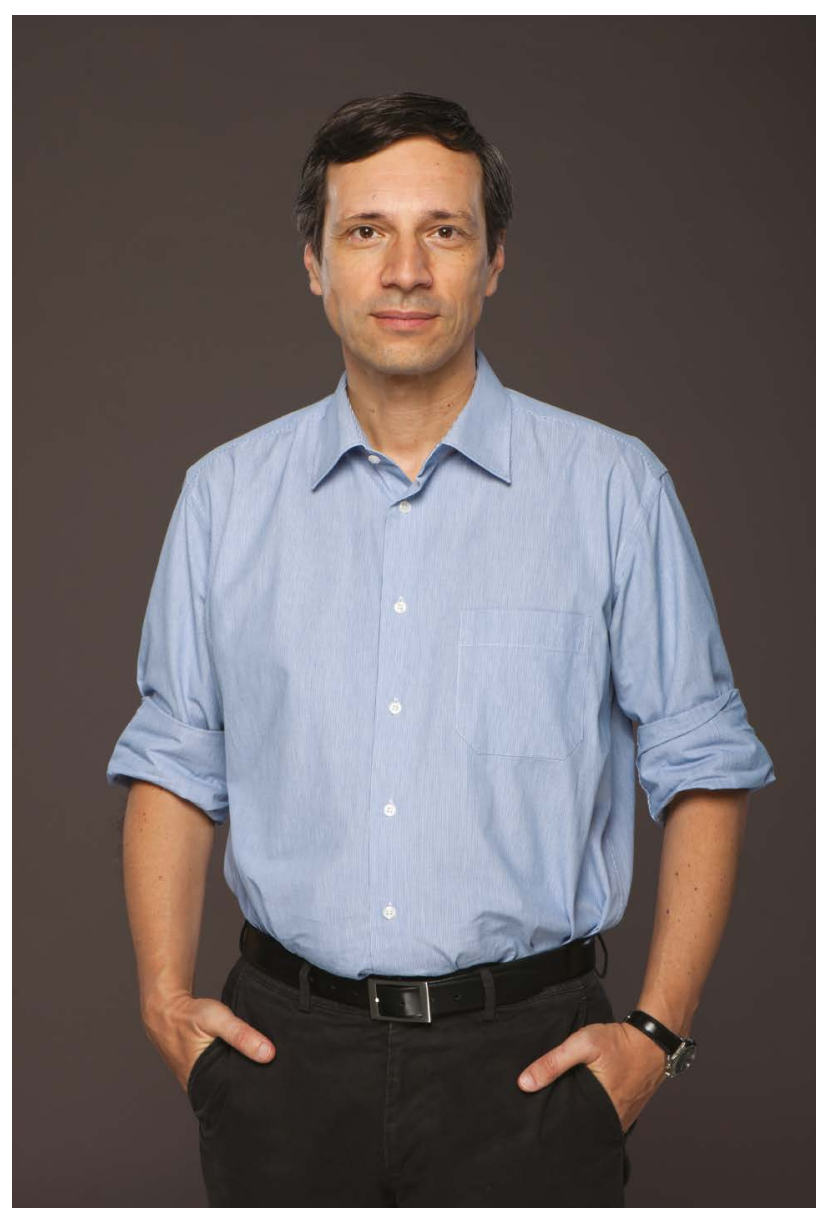

Miguel Augusto Rico Botas Castanho macastanho@medicina.ulisboa.pt
Interação Química com

Maria José Lourenço

mjlourenco@ciencias.ulisboa.pt

Esta Interação Química pretende esclarecer a nossa comunidade científica sobre alguns aspetos da Química envolvidos na atual pandemia e contribuir para uma divulgação mais elucidativa, menos mediática e ausente de pressões políticas e/ou comerciais. 0 convite realizado ao nosso sócio Professor Miguel Castanho, especialista na área da Biofísica Molecular, contribuirá certamente para uma divulgação mais esclarecedora ao público em geral e permitirá ao investigador apresentar a importância dos seus estudos e conhecimentos ao serviço da sociedade.

Estarão as autoridades nacionais a envolver com responsabilidade os cientistas portugueses no plano de ação para a mitigação da COVID-19? Que conhecimentos já existem que podem conduzir a medidas menos proibitivas e mais organizacionais? Que consequências poderão resultar dos excessos de higiene praticados desde março de 2020? Estas e outras questões serão aqui apresentadas, discutidas sobre um inimigo invisível que nos perturba, as armas químicas que temos disponíveis para nos proteger, além de viajar pelo percurso académico e científico do nosso prestigiado investigador.
Miguel Castanho é Licenciado em Bioquímica pela Faculdade de Ciências da Universidade de Lisboa (1990) e Doutorado em Biofísica Molecular pela Universidade Técnica de Lisboa desde 1993. Foi Vice-Presidente da Fundação para a Ciência e a Tecnologia, I.P. Desde 2007 é Professor Catedrático e Diretor do Instituto de Bioquímica da Faculdade de Medicina da Universidade de Lisboa. Dirige o seu grupo de Investigação no Instituto de Medicina Molecular, denominado MCastanho Lab - Physical Biochemistry of Drugs and Targets. Investiga na área de desenvolvimento de novos fármacos para combate à dor, à doença de Alzheimer, a alguns tumores, e a vírus como o HIV e o Dengue.

Recentemente, coordena um consórcio europeu para desenvolver fármacos que protejam o sistema nervoso central da ação de vários vírus, incluindo o SARSCoV-2. Participa regularmente em ações de divulgação científica para públicos não especializados quer em iniciativas públicas presenciais (nas escolas, por exemplo), quer através dos media. É o sócio n. ${ }^{\circ} 2297$ da SPQ e foi editor-adjunto do Boletim "Química” no período compreendido entre 1997 e 1998. 


\section{Gostava que caracterizasses o teu percurso académico e científico.}

Decidi tirar o curso de Bioquímica porque me pareceu muito eclético e próximo da investigaç̧ão científica. Em particular, o curso de Bioquímica da Faculdade de Ciências da Universidade de Lisboa (CIÊNCIAS ULisboa) tinha uma grande componente de Química, Física e Matemática, o que me agradou. Algumas disciplinas do curso foram marcantes, por darem uma perspetiva muito Química-Física da natureza. Na altura de fazer o estágio, juntei-me ao grupo do Professor Manuel Prieto, no Instituto Superior Técnico (IST), vincando ainda mais o ecletismo e a abordagem Biofísica. No IST aprendi muito sobre análise instrumental espectroscópica. A partir daí, desenvolvi sempre a minha atividade cruzando o rigor de uma abordagem instrumental própria da Biofísica com temas relacionados com o desenvolvimento de fármacos, em particular fármacos cujo modo de ação envolve a intervenção de membranas biológicas.

Em 2004 foste distinguido com a Medalha Vicente de Seabra, atribuição pela Sociedade Portuguesa de Química, “by the contribution to the Development of Chemistry and early career" $\mathrm{e}$ foi com toda a certeza um momento muito importante para a tua carreira.

Muito importante, sim. Foi o primeiro prémio que não distinguiu apenas um trabalho específico e concreto. Ao invés, tratou-se do reconhecimento de um corpo de trabalho. No início de carreira isto é muito importante. Fui reconhecido pelos pares pelo caminho trilhado, não apenas por ter cruzado uma meta. Como se faz caminho ao andar, é importante que se olhe para a rota, além dos destinos. 0 prémio deu-me entusiasmo e força para o caminho. São prémios importantes porque, mais do que reconhecimento pelo passado, dão entusiasmo para o futuro; e ganhar o futuro é sempre o valor mais alto.

Que importância tem este prémio e todos os outros para ti, para o Instituto de Medicina Molecular (iMM) e para a ULisboa, em especial para a Faculdade de Medicina da Universidade de Lisboa onde estás inserido?

Para mim, são importantes porque são provas de reconhecimento e são "cafeína" que estimulam a atividade seguinte. Alguns prémios ainda financiam um pouco a nossa atividade de investigação e, em certa altura, tiveram um papel muito importante nesta vertente. Para as organizações que integro (a Faculdade de Medicina da ULisboa e o iMM) o efeito será semelhante. As organizações académicas enquadram e alimentam-se do trabalho dos seus investigadores/ docentes e partilham, por isso, por extensão, o mérito das distinções dadas aos grupos de investigação.

\section{Quantas pessoas constituem atualmente o teu grupo?}

Nunca gostei muito de grupos grandes, hierarquizados e subdivididos. 0 meu grupo tem cerca de 15 pessoas atualmente; antes da pandemia era um número muito flutuante, entre os que saíam para estadias curtas em laboratórios estrangeiros e os visitantes que chegavam de laboratórios estrangeiros. Temos de procurar um equilíbrio entre conseguir avançar para concretizar as ideias que temos e a responsabilidade de encontrar financiamento e tempo para dedicar a todas as pessoas e todos os projetos. Não vale a pena ter um grupo muito grande se não houver sustentabilidade de financiamento e não conseguirmos prestar atenção ao trabalho desenvolvido. 0 nosso trabalho laboratorial é muito diverso, desde as interações moleculares até ao efeito macroscópico no comportamento animal, por exemplo. São condições muito exigentes em multidisciplinaridade e financiamento para conseguir manter um grupo com estas características e acompanhar o ritmo de evolução do estado da arte.

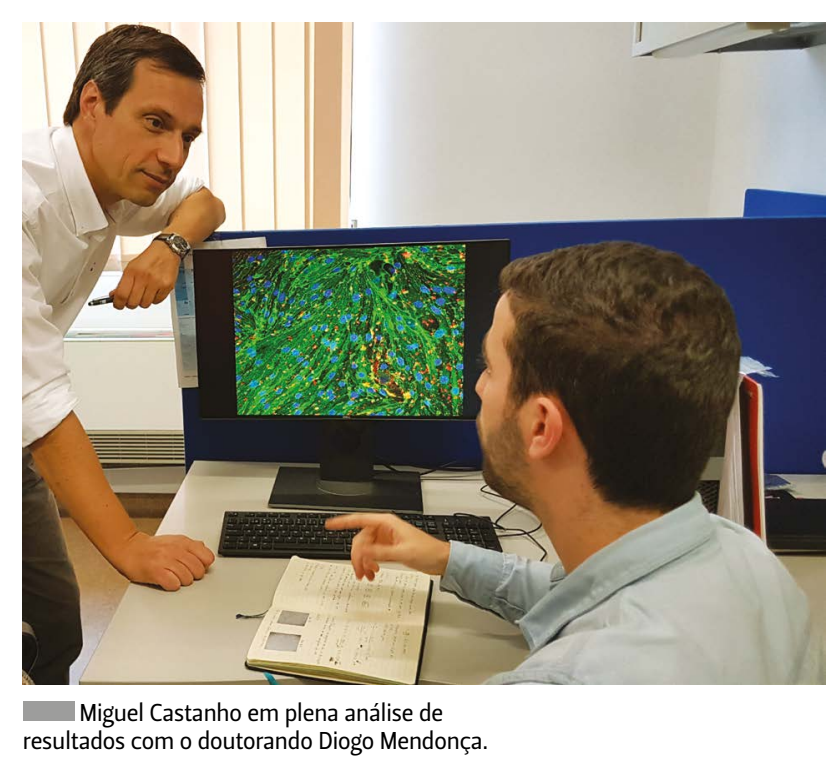

Fala-nos da tua experiência como VicePresidente da FCT.

A Bioquímica é uma ciência experimental: aprende-se fazendo. A Gestão de Ciência também! Só vivendo por dentro do mundo da gestão e administração das instituições científicas sabemos a verdadeira dimensão do que é a Investigação Científica como 
66

\section{A atual situação de pandemia veio trazer muitos olhares e holofotes sobre a Ciência. Há uma aproximação sem precedentes entre jornalistas e cientistas. Esperemos que este impulso não se perca por completo e crie raízes.}

setor de atividade em Portugal. A passagem pela Vice-Presidência da FCT foi enriquecedora e intensa. Ajudou-me a entender as forças e fraquezas do sistema, e os seus males endémicos, que vão muito além do subfinanciamento crónico.

Como caracterizas o acesso ao financiamento na área que escolheste para desenvolver a tua investigação?

Minguante! As taxas de sucesso em concursos nacionais competitivos para financiamento de projetos de Investigação Científica falam por si.

Que análise fazes sobre a cultura científica em Portugal?

Portugal não tem qualquer tradição de cultura científica, tal como tem pouquíssima tradição de participação de cidadania na vida pública. A vida pública tem pouca intervenção de organizações da sociedade civil, incluindo das próprias universidades. Mas é um caminho que está a ser feito, apesar do eclipse da Agência Ciência Viva, por exemplo. As instituições académicas têm feito muito trabalho de promoção da cultura científica, apesar das dificuldades. A atual situação de pandemia veio trazer muitos olhares e holofotes sobre a Ciência. Há uma aproximação sem precedentes entre jornalistas e cientistas. Esperemos que este impulso não se perca por completo e crie raízes.

Que mensagem gostarias de deixar aos jovens investigadores portugueses que estão a realizar os seus trabalhos de doutoramento e ambicionam prosseguir uma carreira de investigação de alto nível?
A primeira mensagem é de distinção entre doutoramento e carreira de investigação; o doutoramento é formação avançada que é útil a muitas carreiras e, sobretudo, à formação de cada um, com o aperfeiçoamento de algumas capacidades humanas, como a maturidade para melhor analisar e melhor decidir. É um passo essencial para uma carreira de investigação, mas não é um passo da carreira de investigação em si. Segunda mensagem: como outras carreiras profissionais em setores criativos, como as artes, vive muito de entrega, convicção, paixão e entusiasmo. Dito de outra forma, vive muito de vocação. Terceira mensagem: embora uma carreira científica exija vocação, é um erro pensar que vive de intuição e inovação permanente. Existem muitos períodos de frustração e trabalho repetitivo e insistente, pouco apelativo. Não é uma tulipa; é uma rosa com espinhos.

O que consideras que pode mudar tendo em conta o período conturbado que o país atravessa?

Como disse antes, espero que o mundo da Comunicação de Ciência tenha um impulso e o mundo dos jornalistas e dos cientistas se sobreponha muito mais do que antes da pandemia. Espero ainda que as doenças infetocontagiosas voltem a constar das agendas das agências de financiamento de Investigação Científica, de onde tinham saído já há muito tempo. 0 sucesso de vacinas e de antibióticos ao longo do século XX fez-nos esquecer dos microrganismos. Vírus, bactérias e fungos têm evoluído mais rapidamente que as nossas terapêuticas. A pandemia da COVID-19 relembrou-nos desta realidade da pior forma, mas as bactérias super-resistentes já deram muitos alertas também.

Numa entrevista ao jornal semanário regional Correio do Ribatejo referes que "a sensibilidade das entidades oficiais responsáveis pela Ciência para as doenças infetocontagiosas é muito baixa. Basta dizer que em 2018 decorreu o primeiro centenário da passagem da Gripe Espanhola e não houve qualquer ato oficial de mínimo relevo". Que motivos justificaram o abandono ao estudo profundo desta gripe?

A amnésia global sobre uma tragédia da dimensão da Gripe Espanhola, que vitimou mortalmente cerca de 2,5\% da população mundial, matando mais gente em 24 semanas do que a SIDA em 24 anos, é intrigante. Como pudemos esquecer? Uma das explicações possíveis é o facto desta tragédia ter coexistido com outra, a I Grande Guerra, e antecedido outra ainda, a II Grande Guerra. A sucessão de devastações fez esquecer a primeira. No entanto, creio que existe ainda 
outra explicação: o facto de se ter criado a sensação de que as doenças infetocontagiosas eram coisas do passado, levou a que deixássemos de sentir um elo de liğação ao que se passou em 1918-1919.

\section{Como se originou a atual pandemia? Há informações seguras vindas da China?}

Não se sabe exatamente. Sabe-se que o primeiro grande surto desencadeador do resto da pandemia foi na China, mas a origem exata do vírus ainda está por estabelecer. Existem dados que apontam para a circulação do vírus antes do surto. Esta situação é típica em todas as pandemias.

\section{Como atua este vírus SARS-CoV-2?}

SARS-CoV-2 é um vírus de RNA, o que quer dizer que tem um determinado potencial mutagénico. O RNA é quimicamente instável devido a reações intramoleculares. Não é por acaso que as nossas células guardam a informação genética sob a forma de DNA, muito mais estável quimicamente. A mutabilidade não é tão elevada como para o HIV ou influenza mas é apreciável. Uma das proteínas da sua superfície, a proteína S (S de Spike), consegue ligar-se especificamente a uma proteína que existe na superfície de algumas células e o processo de infeção segue-se a partir daí. Dá-se o caso dessas células serem sobretudo do sistema respiratório e, por consequência, a doença tem as características que sabemos.

\section{E há uma explicação para que o SARS- CoV-2 não se transmita de forma efetiva através do contacto com as superfícies...}

Um vírus não tem metabolismo próprio nem se multiplica por si só - para isso precisa de uma célula. As moléculas que compõem os vírus e a sua organização são relativamente instáveis, do ponto de vista químico e físico. Dentro do organismo do hospedeiro as condições são ideais para os vírus: a temperatura é constante, o pH é tamponado e o ambiente redox é controlado. Contudo, quando está fora de um organismo vivo, estas condições alteram-se e acrescem reações fotoquímicas se houver exposição à radiação. Temos ainda de considerar que existem perdas de quantidade viral no percurso superfície-mão-cara-vias respiratórias. No global, considerando todos os fatores combinados, seriam necessárias grandes quantidades de vírus para tornar esta via um perigo considerável. $\mathrm{Na}$ maior parte das situações quotidianas, estas quantidades não estão presentes.

\section{Que riscos corremos ao desinfetar muito e muitas vezes as superfícies?}

A obsessão da desinfeção de tudo no ambiente que nos rodeia pode levar ao desenvolvimento de bactérias super-resistentes, além de fazer chegar ao ambiente grandes quantidades de desinfetantes.

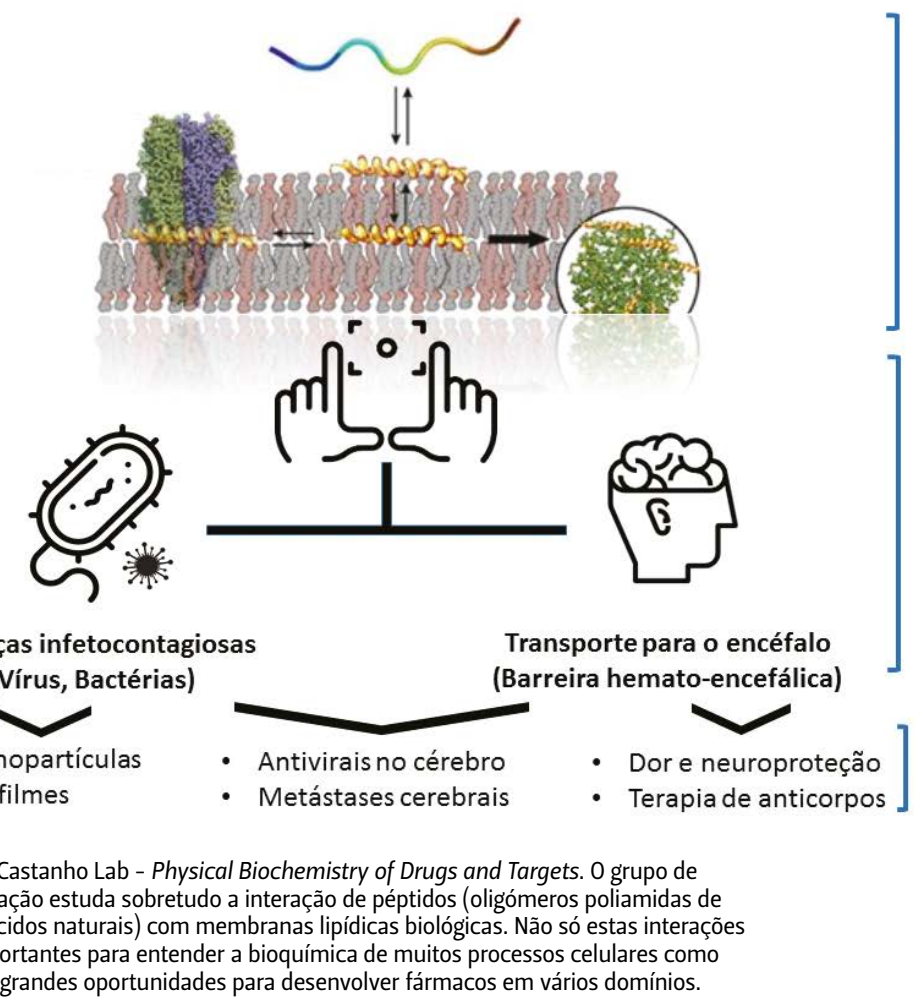

\footnotetext{
MCastanho Lab - Physical Biochemistry of Drugs and Targets. 0 grupo de investigação estuda sobretudo a interação de péptidos (oligómeros poliamidas de são importantes naturais) com membranas lipidicas biologicas. Não só estas interaço oferece grandes oportunidades para desenvolver fármacos em vários domínios.
}

Interação

péptido-membrana

Campos de aplicação
Linhas de trabalho 
66

\section{A Ciência deveria informar} a política e esta decidir em consequência da prova estabelecida. Numa situação como a atual, exigir-se-ia que houvesse uma participação real dos investigadores no processo de identificação e implementação de soluções.

\footnotetext{
Vacina para a COVID-19. Sim? Não? Talvez... Sim, como sempre, desde que se consiga uma vacina segura e minimamente eficaz. 0 calcanhar de Aquiles das vacinas cujo desenvolvimento está mais avançado é que todas estão dependentes de detalhes estruturais da proteína S. Mutações nesta proteína podem tornar as vacinas obsoletas. É preciso investigar e desenvolver novas vacinas, não dependentes da proteína $S$ antecipando mutações futuras do vírus.
}

Não há uma vacina para a gripe e todos os anos temos uma vacina sazonal. Porquê? Persegue-se há muito uma vacina universal para a gripe. Tem sido impossível devido às mutações rápidas do vírus, resultado da instabilidade química do RNA. Desenvolvem-se vacinas atualizadas em cada ano, que se tornam obsoletas no ano seguinte.

Como se pode encarar a logística associada à distribuição de uma vacina a nível mundial?

Existem estratégias diferentes para contrariar a instabilidade do RNA, sendo as mais importantes o uso de baixas temperaturas e o uso de encapsulação em nanoagregados de lípidos. As vacinas de RNA em si diferem na eficácia dos nanoagregados, o que quer dizer que requerem temperaturas diferentes para conservação e manuseio. As temperaturas de operação, por sua vez, determinam a logística associada. É curioso ver como o detalhe microscópico do adjuvante da molécula principal vai determinar a macroscopia da logística do transporte aéreo, por exemplo. É o efeito borboleta ao vivo, mesmo em frente dos nossos olhos.
Para Robert Samuel Langer não há impossíveis. A grande sinergia de conhecimentos proveniente da Química, Engenharia Química, Ciência dos Materiais e Medicina será o suporte da compreensão destes fenómenos difíceis de descobrir. Com formação de Engenheiro Químico e forte experiência na área farmacêutica será que os ensaios da empresa Moderna ganharão prioridade, ou serão os testes clínicos que controlarão o processo de resposta humana?

O processo de criação é sempre o mais importante. É aí que se joga todo o avanço. A vantagem de uma empresa sobre outra pode jogar-se num detalhe "acessório" para o fenómeno biológico em si. Os testes clínicos convencionais vêm confirmar, ou não, segurança e eficácia, mas são apenas o que o nome indica: testes. A criação e a inovação estão a montante e exigem pensamento à escala molecular. Desenvolver fármacos e vacinas é manipular interações moleculares; é algo intrinsecamente químico.

O que é que já aprendemos com esta pandemia?

O valor da colaboração científica à escala global, a revalorização da Ciência como bem da Humanidade e a consciência que não deixámos de fazer parte da Natureza.

Como é que a Ciência em Portugal deveria ter um papel de destaque na atual pandemia? A Ciência deveria informar a política e esta decidir em consequência da prova estabelecida. Numa situação como a atual, exigir-se-ia que houvesse uma participação real dos investigadores no processo de identificação e implementação de soluções. Em vez disso, o Ministério da Ciência, Tecnologia e Ensino Superior (MCTES) não tem qualquer protagonismo e ninguém do mundo da investigação assume o papel de ser o rosto da responsabilidade das medidas que estão a ser tomadas a nível político. 0 papel da Ciência em Portugal resume-se ao auxílio a órgãos de comunicação social, descodificando informação científica e estabelecendo a ponte entre Ciência e Sociedade.

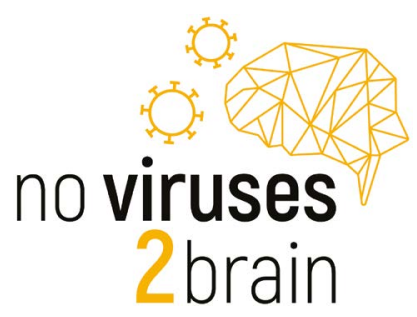

Logotipo do projeto NOVIRUSES2BRAIN, coordenado por Miguel Castanho e financiado pelo European Innovation Council com cerca de $4 \mathrm{M} €$. 0 consórcio abrange três equipas europeias. 


\section{A SPQ tem grande impacto no mundo da Educaçẫo em Química em Portugal. É preciso apoiar quem ensina para que os professores constituam uma "linha da frente" contra a iliteracia científica e o desinteresse.}

Num curto espaço de tempo celebrámos dois anos internacionais dedicados à área da Química; em 2011 o Ano Internacional da Química e em 2019 o Ano Internacional da Tabela Periódica. Estarão os portugueses cientes que a Química contribui decisivamente para a satisfação das necessidades da sociedade moderna? Será que a sociedade já se esqueceu dos problemas que existiam no planeta em dezembro de 2019?

Não se esqueceu, mas colocou outra prioridade à frente. Os problemas de saúde são normalmente percecionados como prioritários, ofuscando outros, mesmo os muito importantes para o futuro da Humanidade. Digamos que a combinação da natureza do problema (Saúde Humana) com a sua urgência foi uma combinação fatal para o destaque aos problemas ambientais. É urgente relembrar que os problemas se somam, não se excluem entre si. A pandemia somouse aos problemas ambientais, não os substituiu. A comunidade científica tem de relembrar a sociedade desta realidade. Os Químicos estão bem posicionados para o fazer por serem peças-chave das soluções, quer no domínio da Saúde Humana, quer do Ambiente.

Como é que a SPQ pode interferir? Será necessário fabricar mais álcool gel? Estarão reunidas as condições para que a QUÍMICA seja uma das protagonistas desta pandemia?

Não é necessário mais álcool gel; é preciso mais e melhor informação sobre o papel da Ciência na resolução de problemas no mundo de hoje. A SPQ tem grande impacto no mundo da Educação em Química em Portugal. É uma agente privilegiada para advogar pela construção científica através dos professores. É preciso apoiar quem ensina para que os professores constituam uma "linha da frente" contra a iliteracia científica e o desinteresse.

Para além do trabalho de investigação e docente, estás envolvido noutras vertentes. Gostarias de referir-te sumariamente a essas atividades e a satisfação pessoal que retiras de cada uma delas?

Retiro grande prazer da poesia, da arte em vidro e cristal, e da pesca. São formas alternativas à Ciência para abordar a Natureza: a poesia tem a criatividade de interrogar e elaborar respostas, como a Investigação Científica; a arte em vidro e cristal tem a beleza e magia da interação radiação-matéria, como a espectroscopia; e a pesca encaixa-nos no puzzle da Natureza como uma peça. Também gostaria de fazer cinema: a criatividade de interrogar, a magia da luz e a concertação de mundos estão todas lá.

Por agora a nossa interação terminou. À data de hoje sabemos mais e o conhecimento adquirido permite que enfrentemos o futuro com segurança convictos que a Química e as suas áreas afins podem resolver problemas da Humanidade.

Miguel, foi um gosto a tua entrevista e muito obrigada pelo tempo disponibilizado.

Obrigado pelo convite e um grande abraço para o Química.

(realizada a 4 dezembro de 2020) 